\title{
CLIL I ERASMUS JAKO TRENDY DYDAKTYCZNE BĘDĄCE ODPOWIEDZIĄ NA ROSNĄCĄ RÓŻNORODNOŚĆ JEZZYKOWĄ I KULTUROWĄ KONTYNENTU EUROPEJSKIEGO
}

SŁowa Kluczowe: Clil, Erasmus, Pokolenie Y, nauczanie JęZyków obCych, Unia EUROPEJSKA

\section{WSTĘP}

Słowa Franka Smitha, wybitnego psycholingwisty czasów współczesnych, brzmiące "Jeden język ustawia Cię w korytarzu życia. Dwa języki otwierają każde drzwi po drodze" w doskonały sposób obrazują, jak znaczącą rolę języki obce odgrywają w życiu każdego człowieka. Poza korzyściami materialnymi czy nieograniczoną swobodą i łatwością podróżowania wynikającymi ze znajomości jednego lub więcej języków obcych, nie należy zapominać, że opanowanie zdolności posługiwania się kolejnym językiem często przyrównane jest do nabycia nowej duszy czy wykształcenia odmiennych perspektyw na życie [Larsen-Freeman, Anderson 2011: 221]. Biorąc pod uwagę fakt, iż znajomość języków obcych wpływa pozytywnie zarówno na fizyczne, jak i mniej namacalne aspekty życia człowieka, kształtowanie jednostek nie tylko bilingualnych, ale i nawet multilingualnych stało się zadaniem priorytetowym krajów Unii Europejskiej [Coyle, Hood, Marsch 2010: 155]. Tytuł jednego z projektów wydanych przez Unię Europejską, który w thumaczeniu na język polski brzmi ,Jak różnorodność językowa może wzmocnić Europę" [European Commission 2007], luźno nawiązuje do tytułu poniższego artykułu, zwracając szczególną uwagę na wielojęzyczność i wielokulturowość społeczeństw kontynentu europejskiego. Warto podkreślić, iż słowa te dają jednocześnie świadectwo tego, iż owa wielowymiarowa lingwistyczna oraz kulturowa różnorodność przyczynia się do większej atrakcyjności kontynentu europejskiego, a nawet może zostać określona mianem jej waloru.

$\mathrm{Na}$ wstępie warto podkreślić fakt, iż Europa od samego początku toczenia się rozmów na temat zwiększenia jej jedności ekonomicznej w latach 50. XX wieku 
skazana była na wysoki poziom wielojęzyczności. Chęć zbudowania i utrzymania gospodarczo zunifikowanej wspólnoty krajów europejskich pociągała za sobą konieczność zwrócenia szczególnej uwagi na edukację językową, a w konsekwencji nacisk położony na politykę nauczania języków obcych. Dokument wydany przez Europejską Wspólnotę Gospodarczą w roku 1958 określił, które z języków w nowo rozwijającej się unii krajów będą językami oficjalnymi, co zaowocowało poświęceniem większej uwagi systemom edukacyjnym, których głównym zadaniem było zapewnienie edukacji językowej rosnącej liczbie młodych ludzi [Tender, Vihalemm 2009: 42; Coyle, Hood, Marsch 2010: 8]. W roku 1978 Komisja Europejska zaproponowała państwom członkowskim nauczanie w szkołach przy pomocy więcej niż jednego języka, co stało się katalizatorem do powstania CLIL-u, któremu więcej uwagi zostanie poświęcone w dalszych częściach artykułu [Coyle, Hood, Marsch 2010: 8].

\section{JĘZYK A KULTURA}

Przedstawiając zagadnienie wielojęzyczności i wielokulturowości kontynentu europejskiego, warto zwrócić uwagę na definicję języka i kultury oraz zastanowić nad relacją istniejącą pomiędzy tymi dwoma pojęciami. W zależności od dyscypliny naukowej spotyka się w literaturze różne podejścia do pojęcia języka, a jego definiowanie zależy od przyjętej teorii. Jednakże, mówiąc najprościej, język można przedstawić jako zbiór dźwięków i symboli, przy pomocy których jednostki mogą się między sobą komunikować [Brown 1994: 4]. Kultura zaś określana jest mianem wartości, tradycji czy rytuałów wyznawanych i praktykowanych przez grupę ludzi. Każde społeczeństwo może obejmować jednostki posługujące się różnymi językami, a przez to wychowane według odmiennych kultur [Lazear 1999: 96]. Zrozumienie relacji pomiędzy językiem a kulturą jest istotne nie tylko dla osób biorących udział w procesie uczenia się i nauczania języków obcych, ale i dla jednostek posługujących się językiem ojczystym. Innymi słowy, wpływ otaczającej kultury wywiera wrażenie na użytkownikach danego języka i nie pozostaje obojętny dla samych środków językowych i sposobu, w jaki ludzie komunikują się między sobą. Struktura języka wpływa bowiem na sposób postrzegania świata, zaś wartości zdobyte poprzez wychowanie $\mathrm{w}$ duchu danej kultury determinują sposób użycia języka [Elmes 2013: 11-12]. Benjamin Whorf we współpracy z Edwardem Sapirem sformułowali prawo relatywizmu językowego ${ }^{1}$, które podkreśla rolę języka w kształtowaniu myśli [Brown 1994: 37]. Ten dość złożony związek pomiędzy językiem a kulturą nie pozostaje obojętny dla polityki nauczania języków obcych. Ze względu na to, że język i kultura wchodzą w interakcję ze sobą na każdym kroku, uwzględnienie roli danego języka i nieodłącznej od niego kultury powinno stanowić bazę, na którym nauczanie języków się opiera [Chłopek 2008: 11].

${ }^{1}$ Ang. Sapir-Whorf hypothesis/Linguistic relativity/Whorfianism - teoria, która określa, że struktura języka wpływa na rozwój poznawczy czy światopogląd człowieka. 


\section{SŁOWA UWARUNKowANE KULTUROWO}

Wątpliwości nie ulega fakt, iż jest to ogromne wyzwanie dla nauczycieli języków obcych, aby wyposażyć swoich uczniów nie tylko w zdolności posługiwania się językiem obcym w sposób płynny i poprawny, ale i wiedzę umożliwiającą im dostosowanie go do różnych sytuacji. Sytuacje te, $\mathrm{z}$ którymi użytkownicy języka obcego mają do czynienia, mogą się diametralnie różnić od tych, które są ogólnie przyjęte i traktowane jako naturalne w ojczystej społeczności - ze względu na to, że pomiędzy kulturami poszczególnych społeczeństw istnieją znaczne rozbieżności w sposobie zachowania rodzimych uczestników danej kultury czy chociażby częstotliwości występowania określonego zjawiska, często dochodzi do sytuacji, w których źródłem porażek w komunikacji interkulturowej są słowa uwarunkowane kulturowo (ang. culture specific words). Ich mianem określa się słowa lub wyrażenia mające charakterystyczne znaczenie dla danej kultury i odzwierciedlające historię lub zwyczaje danej społeczności [Yuewu, Qin 2015: 63-64]. Często jakieś zjawisko lub obiekt nie są spotykane w danej kulturze, a w konsekwencji społeczeństwo żyjące w tej kulturze nie wytworzyło jakichkolwiek środków lingwistycznych do ich opisu. Innymi słowy, znalezienie w danym języku odpowiedników na ich określenie jest często zadaniem niemożliwym, gdyż różne języki wyrażają różne poglądy kulturowe, zachowania czy znaczenia w sposób nie zawsze spotykany w poszczególnych kulturach [Brewster, Ellis, Girard 2002: 146].

\section{CZYNNIKI WPEYWAJĄCE NA ZWIĘKSZONY POZIOM RÓŻNORODNOŚCI EUROPY}

Jak zauważa David Graddol „z punktu widzenia zachodnich cywilizacji wyróżnia się trzy fazy w historii ludzkości: przednowożytną, nowożytną i postmodernistyczną. Wszystkie te okresy charakteryzują się odmiennymi opiniami na temat idei organizacji społeczeństw i ekonomii, różnorodnym światopoglądem czy sposobami postrzegania oczekiwanych zmian. Zmieniające się relacje pomiędzy językami świadczą o zbliżającym się nieuchronnie schyłku czasów nowożytnych" [Graddol 2006: 18]. Czasy nowożytne sięgają swymi korzeniami epoki renesansu, a ich obecność wyczuwalna była w powietrzu przez nadchodzące stulecia. Języki w Europie podczas tego okresu nazywane były językami nowożytnymi - były one bowiem skodyfikowane, znormalizowane, symbolizujące i odzwierciedlające jedność narodową. Jednakże na skutek takich czynników jak globalizacja, rozwój nowych technologii, zacieśnianie współpracy międzynarodowej czy zmiany demograficzne, cała struktura nowożytnej Europy, budowana i wzmacniana na przestrzeni wieków, ulega obecnie modyfikacjom. Nie ulega wątpliwości fakt, że wszystkie te wspomniane przed momentem transformacje mające miejsce nie tylko na gruncie europejskim, ale i całym globie, nie pozostają obojętne dla polityki nauczania języków obcych, modyfikując jednocześnie praktykowane dotychczas modele [Graddol 2006: 19]. 


\section{Pokolenie Y A NAUCZANIE JĘZYKów ObCYCH}

Jak słusznie zauważa Peter Reilly „nauczyciele języka angielskiego z wieloletnim doświadczeniem pracujący na różnych etapach edukacyjnych zdają sobie sprawę, że ich uczniowie myślą i zachowują się inaczej niż ci z poprzednich pokoleń" [Reilly 2012: 2]. W wyniku wszechobecnych zmian modyfikujących organizację i funkcjonowanie społeczeństw czasów współczesnych, zmianie ulega również sposób zachowania współczesnego ucznia, który należy do tak zwanego Pokolenia $Y$ (ang. Generation Y). Członkowie owego pokolenia urodzili się w ciągu ostatnich dwudziestu lat XX wieku, a charakterystycznymi cechami odróżniającymi ich od, na przykład, ciężko pracującego i niezależnego Pokolenia X, które dominowało w latach 1965-1980, są pewność oraz zaangażowanie w użyciu zaawansowanych technologii. Ze względu na inne okoliczności, w których członkowie Pokolenia Y mieli możliwość dorastać i kształtować swoją osobowość, zmieniły się ich oczekiwania w stosunku do metod nauczania praktykowanych w klasie. Mianowicie model transmisyjny nauczania, w którym to nauczyciel odgrywa centralną rolę i stanowi jedyne źródło wiedzy dla uczniów, nie wydaje się być efektywnym sposobem pracy w przypadku Pokolenia Y:

Nauczyciele z doświadczeniem, którzy obracają się w środowiskach edukacyjnych od dłuższego czasu, wiedzą, iż wartości wyznawane przez współczesnych uczniów nie są kompatybilne z formą tradycyjnych kursów czy metodami pracy. Ci, którzy jedynie przerabiają podręcznik mogą być postrzegani jako przestarzali. Dlatego też, efektywność nauczania uwarunkowana jest zdolnością nauczyciela do przystosowania instrukcji odpowiadającej potrzebom współczesnych uczniów [Reilly 2012: 3].

Jak już zostało wspomniane, Pokolenie Y wymaga od nauczycieli poznania jego potrzeb oraz jednoczesnego wypracowania metod pracy, które pomogłyby w zaspokojeniu tych wymogów. Pierwszą cechą charakterystyczną dla owego pokolenia jest umiejętność korzystania z nowoczesnych technologii. Wątpliwości nie ulega fakt, iż zainteresowanie uczniów światem technologii powinno w konsekwencji znaleźć odzwierciedlenie w sposobie organizacji zajęć w oparciu o wykorzystanie owych technologicznych udogodnień. Co więcej, Pokolenie Y oczekuje otrzymania natychmiastowej opinii zwrotnej, tzw. feedbacku od nauczyciela, bezpośrednio po wykonaniu zadania. Zaspokojenie potrzeby feedbacku w procesie nauczania języka obcego jest możliwe dzięki określeniu klarownych strategii uczenia się oraz umiejętnym poprawianiu błędów popełnianych przez uczniów, które nie powinno ograniczać się do wykonanej przez nauczyciela korekty powszechnie stosowanej w edukacji. Wręcz przeciwnie, to uczniowie powinni być zachęcani do samodzielnej poprawy własnych błędów, stając się jednocześnie aktywnymi uczestnikami procesu nauczania. Trzecią cechą Pokolenia Y, która powinna zostać uwzględniona podczas zajęć szkolnych, jest nacisk położony na poczucie sensu wykonywanego zadania i zainteresowanie tematem. Oznacza to, że uczniowie chcą uczyć się tematów ciekawych dotyczących ich życia i środowiska w sposób stymulujący i produktywny [Reilly 2012: 4-9]. 
Zgodnie z tym jak Hanna Komorowska opisuje kompetencje uczniów rozwijane w procesie nauczania języków obcych, początkowo ich doskonalenie ograniczało się jedynie do rozwoju świadomości językowej, która „dotyczy rozumienia mechanizmów funkcjonowania języka i świadomości różnic znaczeniowych, (...) wiedzy o tym jak różnicują się środki językowe w zależności od sytuacji, miejsca, osoby, rozmówcy, treści komunikatu i intencji mówiącego" [Komorowska 2007: 188]. Dopiero z czasem zaczęto dostrzegać znaczenie kultury i rozwoju kompetencji interkulturowej obejmującej wiedzę ucznia o społeczeństwie i kraju, który posługuje się językiem docelowym jako ojczystym [Komorowska 2007: 188]. Innymi słowy, obowiązek nauczania o stylu życia i niewerbalnych sposobach komunikacji kultury społeczeństwa posługującego się językiem docelowym wraz z rozwijaniem kompetencji językowych został uznany przez lingwistów jako klucz do sukcesu w nauce języka [Tomalin, Stempleski 1993: 6, Brewster, Ellis, Girard 2002: 146-147].

\section{REAKCJA EUROPY NA OBECNE ZMIANY}

Wiele podejść do nauczania języków obcych praktykowanych było na przełomie ostatnich kilku dekad: od metody gramatyczno-tłumaczeniowej czy podejścia audiolingualnego do rozsławionego podejścia komunikacyjnego. Jednakże, jako następstwo różnorodnych zmian spoza dziedziny glottodydaktyki, będących konsekwencją rozwoju technologicznego oraz globalizacji zapoczątkowanych od początku XX wieku, metody nauczania i uczenia się języków obcych uległy modyfikacji. Mianowicie, środowisko klasy szkolnej nie stanowi jedynego miejsce nauczania języka obcego, gdyż dzięki udogodnieniom zaoferowanym przez technologię uczenie się języka obcego może stać bardziej autonomicznym przedsięwzięciem [Larsen-Freeman, Anderson 2011: 220-221]. Wymienione powyżej podejścia, ze względu na zmiany organizacyjne społeczeństw i ich światopogląd, nie spełniały swoich dydaktycznych funkcji, nie przynosząc jednocześnie upragnionych efektów.

\subsection{CLIL}

Odmienny rozdział w historii nauczania języków obcych zajmuje CLIL - aby zrozumieć, dlaczego edukacja oparta na podejściu CLIL-owym cieszy się rosnąca popularnością, niezbędne jest przedstawienie kluczowych wiadomości dotyczących tego pojęcia. CLIL jest to termin z języka angielskiego utworzony ze słów Content and Language Integrated Learning, a w języku polskim funkcjonujący pod nazwą Zintegrowane ksztatcenie przedmiotowo-językowe. Owego terminu używa się do opisu podejścia do nauczania zarówno przedmiotu niejęzykowego z programu nauczania, jak i języka obcego. Mówiąc prościej, jest to „,nauczanie przedmiotu takiego jak geografia, przedmioty ścisłe czy historia przez język, który nie jest językiem pierwszym uczniów, czyli ich językiem ojczystym" [Thornbury 2006: 5]. Podejście to powstało w latach 90. XX wieku w Europie i od momentu jego wprowadzenia w 1996 roku zdobywa na popularności, nie będąc już enigmatycznym akronimem w środowiskach edukacyjnych. Powodami, dla których idea CLIL-u została zapoczątkowana były „ambicje Unii Europejskiej do znalezienia efektywnego 
programu nauczania języków obcych, który pomógłby osiągnąć jej cele, takie jak znajomość przez wszystkich mieszkańców dwóch języków obcych, jedność społeczna, zwiększona mobilność w jej granicach oraz wzmocniona siła gospodarcza" [Georgiou 2012: 495]. To dzięki podwójnej uwadze poświęconej zarówno treści, jak i językowi, zintegrowane kształcenie przedmiotowo-językowe różni się od swoich glottodydaktycznych poprzedników [Georgiou 2012: 495].

Podstawowe wiadomości dotyczące pojęcia CLIL-u odnoszące się do jego nazewnictwa oraz okoliczności powstania zostały już przedstawione, czas więc teraz nakreślić metodologię CLIL-u, która posiada kilka cech wspólnych z silną formą podejścia komunikacyjnego. Pierwszą z nich jest brak zorganizowanego sylabusa czy programu językowego, na którym nauczanie byłoby oparte, a także nacisk położony na doskonalenie umiejętności komunikacyjnych [Thornbury 2006: 5]. Jednakże w przypadku CLIL-u to użycie języka w sytuacjach autentycznych odnoszących się do tematów realnych znajduje się na pierwszym planie. Dużo wsparcia dla uczniów podczas pracy na zajęciach oraz korzystanie $\mathrm{z}$ różnorodnych strategii mających na celu aktywizację bądź ułatwienie przyswajania problematycznego materiału, to kolejne charakterystyczne cechy CLIL-u [Deller, Price 2007: 9]. Co więcej, uwzględnianie elementów kulturowych podczas każdych zajęć zgodnie z modelem „4Cs” opracowanym przez Do Coyle, pozwalającym na interakcję pomiędzy czteroma elementami, tj.: treść, język, poznanie i kultura, rozwój uczniów legitymujących się nie tylko płynnością i poprawnością, ale wrażliwością i tolerancyjną postawą w stosunku do innych kultur w myśl świadomości interkulturowej jest umożliwiony [Coyle, Hood, Marsch 2010: 41].

\subsection{ERASMUS +}

Początki istnienia wymian studenckich można datować na koniec wieku XIX, a ich główna idea nie miała wiele wspólnego z rozwijaniem zdolności językowych, gdyż za główny cel dziewiętnastowiecznych wymian studenckich uważało się budowanie i podtrzymywanie pokojowych relacji pomiędzy państwami. Jednakże zwiększająca się integracja polityczna i ekonomiczna Europy zaowocowała powstaniem różnorodnych organizacji i programów, które promują image zjednoczonej Europy [Muller-Hartmann 2004: 211]. Program Erasmus + jest to program Unii Europejskiej na lata 2014-2020 obejmujący obszary edukacji, treningu, młodych ludzi i sportu sponsorujący współpracę we wszystkich tych sferach pomiędzy krajami członkowskimi Europy a ich partnerami na całym świecie. Program ten został rozwinięty przez Komisję Europejską w Brukseli, a został powołany do życia przez Agencję Wykonawczą ds. Edukacji, Kultury i Sektora Audiowizualnego [European Commission 2015: 7-8]. Wszystkie projekty znajdujące się pod patronatem programu Erasmus + obierają za swoje główne cele opanowanie przez swoich wychowanków różnorodnych umiejętności niezbędnych do funkcjonowania $\mathrm{w}$ zróżnicowanych środowiskach Europy poprzez pogłębianie wiadomości o obcych kulturach i naukę języka. Co więcej, uczestnictwo w wymianach studenckich zaoferowanych przez 
program Erasmus+ zapewnia jego uczestnikom nie tylko rozwój zawodowy, ale także przeżycie niezapomnianej przygody [Lesjak i inni 2015: 846]. Jak można przeczytać w dokumencie wydanym przez UE, „wielojęzyczność to kamień węgielny projektów europejskich i potężny symbol Europy w dążeniach do osiągnięcia jedności”. Co więcej, ,promocja nauki języków oraz lingwistycznej różnorodności to jedne z głównych priorytetów programu" [European Commission 2016: 10]. Znajomość języków obcych jest kluczową cechą, jaką każdy mieszkaniec zjednoczonej Europy powinien się charakteryzować, gdyż brak takich umiejętności odbiera szansę na aktywne i owocne uczestnictwo w programach europejskich dotyczących sfer edukacji, treningu czy sportu.

\section{Podsumowanie}

Przed Europą dążącą do osiągniecia politycznej, ekonomicznej i społecznej jedności twardy orzech do zgryzienia - „,chęć zmniejszenia poziomu bezrobocia pomiędzy młodymi mieszkańcami rezygnującymi z edukacji zbyt wcześnie, kwestia ludzi dorosłych ze zbyt niskimi kwalifikacjami, wpływ ciągle rozwijającej się technologii i potrzeba umiejętności korzystania $\mathrm{z}$ tych udogodnień, nacisk położony na talent i innowację, nadanie jednoczących właściwości edukacji wyrównującej szanse ludzi pochodzących z ubogich czy marginalizowanych środowisk" - to niektóre z problemów, z którymi Unia Europejska będzie musiała sobie poradzić w chwili obecnej, a także i w najbliższej przyszłości [European Commission 2016: 7]. Wyzwania dla Unii Europejskiej wydają się być trudne, jednakże z pomocą trendów dydaktycznych, jak CLIL i program Erasmus + , kształtowanie społeczeństw w duchu europejskim od najmłodszych lat jest osiągalnym przedsięwzięciem. Jest to możliwe dzięki temu, że to właśnie założenia i cele programów CLIL i Erasmus w przeważającej mierze odzwierciedlają misję Unii Europejskiej polegającą na kształtowaniu jednostek będących w stanie komunikować się efektywnie w różnych okolicznościach, żyjąc jednocześnie w środowisku europejskim, w którym granice pomiędzy jej członkami powoli zanikają, tworząc spójną i harmonijną jedność.

\section{Bibliografia}

Brewster J., Ellis G., Girard D. [2002], The primary English teacher's guide, Pearson Education, Harlow.

Brown H.D. [1994], Principles of language learning and teaching, Prentice Hall Regents, New Jersey.

ChŁopeK Z. [2008], The intercultural approach to EFL teaching and learning, "English Teaching Forum", nr 4.

Coyle D., Hood P., Marsch D. [2010], CLIL: content and language integrated learning, Cambridge University Press, Cambridge; New York.

Deller S., Price C. [2007], Teaching other subjects through English, Oxford University Press, Oxford. 
Elmes D. [2013], The relationship between language and culture, http://scholar. google.pl/scholar?q=david+elmes + the + relationship+between+language + and + culture $\& \mathrm{hl}=\mathrm{pl} \&$ as $\mathrm{sdt}=0 \&$ as_vis $=1 \& \mathrm{oi}=$ scholart\&sa $=\mathrm{X} \& \mathrm{ved}=0$ ahUKEwiTm OX-k-nPAhVIFSwKHSRIDOkQgQMIITAA.

European Commission [2015], Erasmus + programme, http://bookshop.europa.eu/ en/the-erasmus-programme-pbEC0115429/.

European Commission [2016], Erasmus + programme guide, http://www.google. $\mathrm{pl} / \mathrm{url}$ ? $\mathrm{sa}=\mathrm{t} \& \mathrm{rct}=\mathrm{j} \& \mathrm{q}=\&$ esrc $=\mathrm{s} \&$ source $=$ web $\& \mathrm{~cd}=1 \& \mathrm{ved}=0$ ahUKEwjphZe FlnPAhUC1iwKHTZtBH8QFggjMAA\&url=http\%3A\%2F\%2Fec.europa. eu $\% 2$ Fprogrammes $\% 2$ Ferasmus-plus $\% 2$ Fsites $\% 2$ Ferasmusplus $\% 2 \mathrm{Ffiles} \% 2 \mathrm{Ffil}$ es\%2Fresources\%2Ferasmus-plus-programme-guide_en.pdf\&usg=AFQjCNF_ 9BliKYnAie9b4undNoyely5hwQ.

European Commission [2007], A Rewarding Challenge: How the multiplicity of languages could strengthen Europe.

Georgiou S.I. [2012], Reviewing the puzzle of CLIL, "ELT Journal”, nr 4, http://eltj. oxfordjournals.org.oxfordjournals.han.bg.umcs.edu.pl/content/66/4/495.

Graddol D. [2006], English next, British Council, Plymouth.

KomorowsKa H. [2007], Metodyka nauczania języków obcych w Polsce (19572007), Wydawnictwa Centralny Ośrodek Doskonalenia Nauczycieli, Warszawa.

Larsen-Freeman D., Anderson M. [2011], Techniques and principles in language teaching, Oxford University Press, Oxford.

Lazear E.P. [1999], Culture and language, "Journal of Political Economy", nr 6.

Lesjak M., Juvan E., Ineson E. M., Yap M., Podovšovnik Axelsson E. [2015], Erasmus student motivation: Why and where to go?, "High Educ", nr 5, http://link. springer.com.springer.han.bg.umcs.edu.pl/article/10.1007/s10734-015-9871-0.

Muller-Hartmann A. [2004], Exchanges, [w:] Routledge encyclopedia of language teaching and learning, Byram M. (red.), Routledge, Oxon, New York, s. 211-213.

ReILly P. [2012], Understanding and teaching generation Y, "English Teaching Forum", nr 1.

Tender T., Vihalemm T. [2009], Two languages in addition to mother tongue - Will this policy preserve linguistic diversity in Europe?, "Trames", $\mathrm{nr}$ 1, http://www. kirj.ee.kirj.han.bg.umcs.edu.p1/14797/.

Tomalin B., Stempleski S. [1993], Cultural awareness, Oxford University Press, Oxford.

Thornbury S. [2006], An A-Z of ELT. A dictionary of terms and concepts, Macmillan Publishers Limited, Oxford.

Yuewu L., I QIN Y. [2015], An investigation into the culture-loaded words learning by English majors in a vocational college in China, "English Language Teaching", nr 8, http://www.ccsenet.org/journal/index.php/elt/article/view/51403/27560. 